\title{
Astronomía en la escuela: una investigación del juego de construcción de constelaciones.
}

\author{
Ariadna da Silva $\mathrm{Ama}^{1}$ \\ Juliana Eugênia Caixeta ${ }^{2}$ \\ Paulo Eduardo de Brito $^{3}$
}

\begin{abstract}
Resumen
Esta investigación tuvo como objetivo conocer las concepciones que los estudiantes del sexto grado tienen acerca de las constelaciones creadas por ellos a partir del juego de construcción. Se realizó una encuesta cualitativa. La mayoría de ellos entienden la constelación como el conjunto de estrellas, los demás estudiantes la entienden como el cielo o como una sola estrella. La investigación demostró que el uso del juego de construcción de constelaciones fue útil para identificar los conceptos que los estudiantes tenían sobre las constelaciones. A partir de esta identificación en el juego, que surge al analizar las imágenes y narraciones, es posible que los maestros de educación básica ejecuten acciones pedagógicas que fomenten la enseñanza de conceptos de astronomía.
\end{abstract}

Palabras clave: astronomía, constelaciones, constelaciones de construcción del juego.

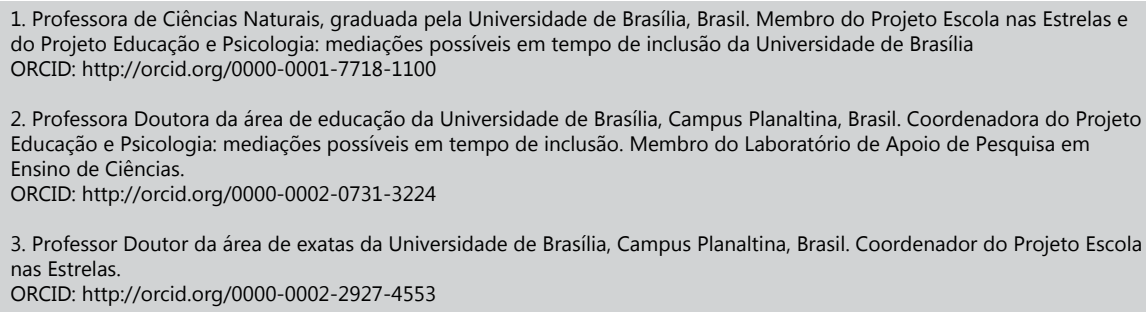

2. Professora Doutora da área de educação da Universidade de Brasília, Campus Planaltina, Brasil. Coordenadora do Projeto Educação e Psicologia: mediações possíveis em tempo de inclusão. Membro do Laboratório de Apoio de Pesquisa em Ensino de Ciências.

ORCID: http://orcid.org/0000-0002-0731-3224

3. Professor Doutor da área de exatas da Universidade de Brasília, Campus Planaltina, Brasil. Coordenador do Projeto Escola 


\title{
Astronomy at school: a research of the game building constellations.
}

\begin{abstract}
This research aimed to know the conceptions that students of the sixth grade of elementary school build on constellations created by them from the game Building constellations. A qualitative survey was conducted. Most of them understand constellation as star set, the other students understand constellation as heaven or as a single star. The research showed that the use of Game Building Constellations was useful for identifying concepts that sixth graders had about constellations. From this identification, arising by analyzing the images and narratives attached to them, in the game, it is possible that the basic education teachers outlining pedagogical actions that will encourage the teaching of astronomy concepts.
\end{abstract}

Keywords: astronomy, constellations, game building.

Recibido: 06-07-2015

Aceptado: 14-09-2015

\section{Introdução}

O céu noturno desperta interesse dos seres humanos há muitos anos, seja pela sua beleza; seja pelos enigmas que ele esconde. Segundo Livi (1987), o céu sempre exerceu fascínio sobre o ser humano e está registrado no legado de todas as civilizações. O fascínio pelo céu independe da idade e isto foi comprovado pelo projeto Escola nas Estrelas, que tem por objetivo divulgar a astronomia e a cosmologia em escolas públicas e privadas do Distrito Federal e região (Santos, 2011). Nas ações realizadas nas diversas escolas, foi percebido o interesse dos alunos pelo céu e também de seus pais e professores, quando acontece a observação noturna, por meio de telescópios.

A relevância desta pesquisa, a partir de imagens, se assenta na compreensão de que a polissemia típica da imagem permite a seus participantes a construção de conhecimentos relacionados à astronomia a partir de suas vivências pessoais, no contexto sócio-cultural. Cada imagem contém um contexto e sentidos próprios que poderão ser construídos por uma análise complexa da mesma. Por isso, imagem e narrativa formam um par harmonioso, que juntas construirão significados (Leite, 1998) e permitirão identificar o conceito que os alunos constroem sobre constelações. 


\section{Astronomia, constelações e cultura}

Segundo Rees (2008), o olho humano sempre enxergou padrões entre as estrelas. Esses padrões seriam as constelações, que são agrupamentos arbitrários de estrelas (Departamento de Astronomia da UFRGS, 2009; Fares, Martins, Araújo, Filhos, 2004; Mourão, 2001). A partir dessa visualização de padrões, várias civilizações antigas, como a greco-romana, egípcia, persa e outras, como os índios brasileiros, construíram constelações e histórias que explicassem a existência delas (Departamento de Astronomia da UFRGS, 2009).

A relação do ser humano com o céu ocorreu e ocorre pelo encanto e fascínio que o céu exerce sobre o ser humano, que instiga a contemplação celeste; e à necessidade de orientação, que era fundamental para sobrevivência dos povos antigos, pois o mesmos não possuíam outros meios de localização no espaço e tempo, que não fossem as estrelas. A necessidade de orientação motivou o estudo do céu, pois o ser humano há cerca de 8000 anos deixou de ser nômade, passando a ter um lugar fixo de moradia, para onde retornava após o período de caça. Utilizando as estrelas como guias, ele podia se afastar de seu lar na certeza de reencontrá-lo (Fares et al., 2004).

Para facilitar a orientação, os seres humanos passaram a reunir as estrelas em grupos, dando origem às constelações. As constelações respondiam a necessidades práticas para quem as criou como a necessidade de orientação ou a necessidade de conhecer as épocas do ano, pois as constelações serviam para ajudar a identificar as estações do ano, como no caso da constelação de escorpião que é típica do inverno do hemisfério sul, já que nessa época ela é visível à noite toda no céu (Fares et al., 2004).

Nesse contexto, temos que as constelações são fenômenos sociais, ou seja, leituras que os seres humanos fazem do conjunto das estrelas, enquanto fenômeno natural (Fares et al., 2004). Em geral, as constelações representam deuses, mitos, animais e até objetos de uso importante no cotidiano (Departamento de Astronomia da UFRGS, 2009). Os caçadores visualizaram no céu, caçadores e caça, por exemplo, a constelação de Órion (caçador) e a constelação de Leão; os agricultores visualizaram a constelação de Virgem, que, segundo Rees (2008), representa Demeter, a deusa dos grãos na mitologia grega; já os pastores, viram as constelações do Boieiro, Capricórnio e Carneiro (Fares et al., 2004).

De acordo com International Astronomical Union (2014), em 1930, ela mesma reconheceu a existência de 88 constelações conhecidas como ocidentais, algumas dessas constelações são: Aquário, Cruzeiro do Sul, Gêmeos, Órion (Caçador), entre outras.

Segundo Clávia (2010), das 88 constelações reconhecidas pela International Astronomical Union, 48 foram descritas primeiramente pelos gregos antigos. 
Cláudio Ptolomeu (127-145 d.C.), baseando-se em um catálogo de estrelas do astrônomo grego Hiparco (século II a.C.), atualizou-o e organizou as estrelas em 48 constelações, registradas em seu livro Almagesto. De acordo com Rees (2008), não se adicionaram novas constelações as de Ptolomeu até o fim do século 16, quando navegadores holandeses chegaram às Índias Orientais. Lá, podiam observar a parte sul do céu, que na Europa não era possível observar. Dois navegadores, Frederick de Houtman e Pieter Dirkszoon Keyser, catalogaram cerca de 200 novas estrelas austrais, com as quais o mentor deles, o geógrafo holandês Petrus Plancius, criou 12 novas constelações, inserindo-as no catálogo de Ptolomeu. Aproximadamente, um século mais tarde, o astrônomo polonês Johannes Hevelius preencheu as lacunas restantes no céu boreal. Em meados do século 18, o astrônomo francês Nicolas Louis de Lacaille introduziu 14 novas constelações austrais.

As primeiras 48 constelações reconhecidas pela International Astronomical Union são chamadas, segundo Fares et al. (2004), de clássicas. Elas são todas carregadas de magia, poesia e encanto, por simbolizarem, individualmente ou em grupo, algum feito heróico de caçadores, agricultores, deuses, semideuses e heróis. Órion, Touro, Escorpião, Leão e Virgem são exemplos de constelações clássicas.

A partir do século XV, foram criadas as 40 últimas constelações reconhecidas pela International Astronomical Union (2014), devido à exploração da parte sul da Terra pelas grandes navegações europeias, acarretando a criação de novos grupos de estrelas, conhecidas como constelações modernas. Elas foram batizadas com nomes, não mais relacionados com o universo mitológico, mas aos elementos contemporâneos da época, como as constelações da Ave do Paraíso, do Índio, da Bússola, da Serpente Marinha, da Vela e do Microscópio. Portanto, as últimas constelações ocidentais criadas não foram representadas com a mesma magia e encanto das clássicas, isto porque, no período da criação das constelações clássicas, as pessoas acreditavam que deuses governavam o universo; já no período da criação das constelações modernas, ocorre o renascimento cultural e científico, levantando ideias que buscam explicar o universo a partir das leis da física e matemática. Portanto, enquanto os gregos usavam mitos para explicar determinados fenômenos; na era moderna, utilizam-se instrumentos como o telescópio, microscópio e outros (Fares et al., 2004).

As mudanças que ocorrem na forma de cada sociedade se organizar, classificar e viver suas experiências são refletidas nas representações das constelações modernas, que são criadas a partir de imagens obtidas por experiências visuais anteriores concretas, ou seja, representam a natureza em si das coisas, não os supostos criadores dessa natureza. Por exemplo, entre as constelações clássicas temos a constelação do Ofiúco, que faz referência a Esculápio, o deus da medicina, que tinha o poder de ressuscitar os mortos; já entre as modernas, surge a constelação do Microscópio, um dos instrumentos utilizados pela medicina (Fares et al., 2004). 
Recentemente, o aspecto original das constelações, de orientação onde os povos antigos utilizavam as constelações pra se localizar no espaço e tempo e assim tentar garantir sua sobrevivência, perdeu espaço na sociedade, pois, com a revolução industrial e científica, inaugura-se uma nova fase de produção dos bens materiais e simbólicos, necessários à sobrevivência, que dispensa toda aquela simbologia estelar (Ress, 2008; Fares et al., 2004). Hoje, para os astrônomos, as constelações designam uma "região da esfera celeste" (Fares et al., 2004, p. 82). Essas regiões são perfeitamente demarcadas na Esfera Celeste, possuem tamanhos variados e delimitações bem definidas e retilíneas, qualquer objeto celeste que estiver na região de uma constelação, além das estrelas da mesma, é considerado parte da constelação ou região da esfera celeste, esse objeto pode não ter qualquer tipo de ligação astrofísica com os outros objetos pertencentes à constelação, as regiões da esfera celeste são usadas para orientação dos estudos astronômicos (Fares et al., 2004; Centro de Divulgação da Astronomia, 2000).

No decorrer da história das constelações, percebe-se a constante busca humana pelo conhecimento do seu meio físico-natural, necessário para sua sobrevivência, sendo uma busca marcante em qualquer organização social. Como os povos europeus antigos, outros grupos étnicos mapearam o céu para resolver seus problemas (Fares et al., 2004).

Os indígenas brasileiros, por exemplo, utilizam métodos empíricos, relacionando o movimento das constelações com eventos meteorológicos que acontecem ao longo do ano, com períodos de chuva e estiagem, de calor ou de frio (Mariuzzo, 2012). Os tupinambás conheciam muito bem o aglomerado estelar das Plêiades e o denominavam "Seichu", quando elas apareciam no lado leste, ao anoitecer, os índios afirmavam que as chuvas chegariam, chegando efetivamente poucos dias depois (Afonso, 2009). Além de utilizar as constelações para entender eventos meteorológicos, os índios utilizam-nas para orientação geográfica (Afonso, 2009).

Para os tupis-guaranis, as constelações são constituídas pela união de estrelas e, também, pelas manchas claras e escuras da Via Láctea (Afonso, 2006). Existem dois tipos principais de constelação indígena: uma vinculada à natureza e outra, à religião. Nas constelações vinculadas à categoria natureza, estão aquelas relacionadas ao clima, à fauna e à flora do lugar, que é conhecida pela maioria da comunidade, e que regula o cotidiano da aldeia. Já aquelas ligadas à religião, estão relacionadas aos espíritos indígenas, sendo conhecidas, geralmente, apenas pelos pajés (Afonso, 2006).

"Experiências culturais influenciam a forma como as pessoas enxergam um mesmo conjunto de pontos no céu" (Filho \& Germano, 2007:12). Portanto, as constelações refletem a cultura dos diferentes povos que as identificaram no céu noturno (Departamento de Astronomia da UFRGS, 2009). Segundo Clávia (2010), cada povo e tribo possuíam suas próprias constelações, no que, 


\section{Ariadna da Silva Amador, Juliana Eugênia Caixeta, Paulo Eduardo de Brito}

Astronomía en la escuela: una investigación del juego de construcción de constelaciones. Artículo producto de la investigación.

muitas vezes, se tratavam do mesmo conjunto de estrelas, porém com nomes e significados diferentes.

O Departamento de Astronomia da UFRGS (2009) faz uma comparação entre as constelações indígenas e suas equivalentes em outros povos antigos. As figuras 1 e 2 mostram a mesma região do céu vista por diferentes civilizações. $\mathrm{Na}$ primeira figura, a demarcação das constelações é oficial, feita pela International Astronomical Union (IAU, 2014). Na segunda figura, encontramos a constelação do homem velho, segundo a tradição tupi-guarani. A constelação do Homem Velho é formada pelas constelações ocidentais Taurus e Orion (Afonso, sd).

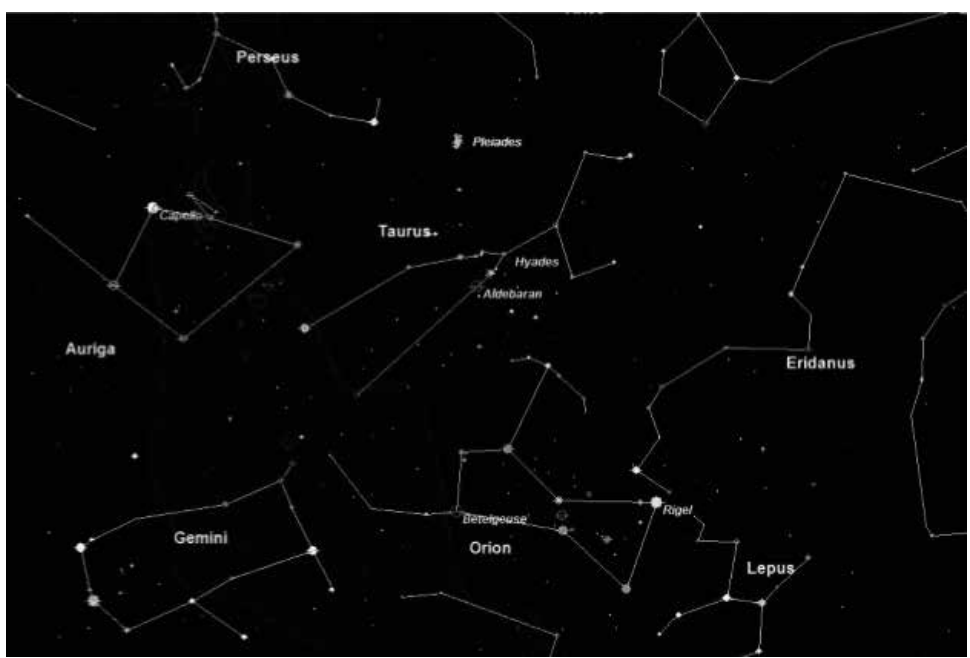

Figura 1: mostra a demarcação da IAU para a herança da visão do céu noturno pelos gregos e romanos. Fonte: Afonso (sd)

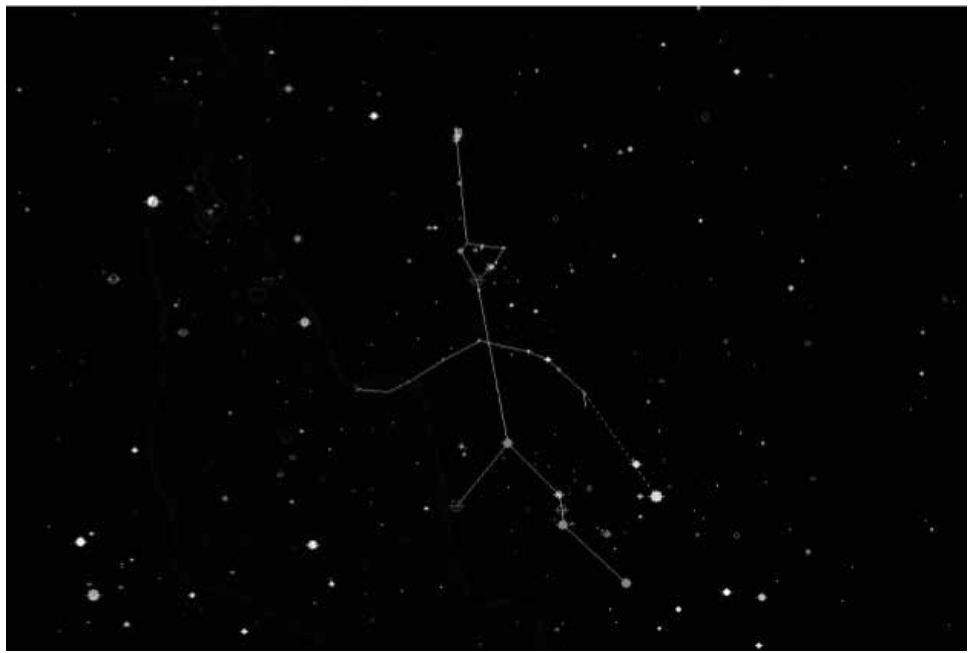

Figura 2: constelação do homem velho, segundo a tradição tupi-guarani.

Fonte: Afonso (sd) 
Para Rees (2008), a partir das relações entre as constelações, os povos antigos ilustravam seus mitos e lendas. Guardar a forma ou a localização dessas figuras no céu não era um trabalho fácil e uma estratégia eficiente se fundamentava na história oral, com a criação de mitos e histórias sobre as constelações (Clávia, 2010). Então, as constelações se tornavam, ao mesmo tempo, ilustração e concretização de crenças para esses povos. A seguir, apresentamos alguns mitos e lendas de duas constelações reconhecidas pela International Astronomical Union (2014), órion e touro, e uma constelação indígena, o homem velho.

Bufinch (2002: 248) narra sobre a Constelação de Óriun (ver figura 1):

Órion viveu, como caçador, com Diana, de quem era favorito, chegandose mesmo a dizer que ela quase se casou com ele. O irmão da deusa, muito desgostoso, censurava-a, freqüentemente, mas em vão. Certo dia, observando Órion que vadeava o mar apenas com a cabeça acima d'água, Apolo mostrou-o a sua irmã, afirmando que ela não seria capaz de alvejar aquele objeto negro sobre o mar. A deusa caçadora lançou um dardo, com pontaria fatal. As ondas empurraram para a terra o cadáver de Órion e, percebendo, com muitas lágrimas, seu erro, Diana colocou-o entre as estrelas, onde ele aparece como um gigante, com um cinto, a espada, a pele de leão e uma clava. Sírius, seu cão, o acompanha.

Segundo Pouzadoux (2001) e Costa (2009), a narrativa da Constelação de Touro (ver figura 1) tem a ver com a paixão de Zeus por Europa, filha do rei Agenor. Para conhecê-la melhor, Zeus aguardou o momento em que Europa brincava com suas amigas na praia e decidiu transformar-se num grande touro branco. Europa ficou encantada com o esplendor do animal e a ternura do seu olhar. Sem medo do tamanho do touro, ela se aproximou dele, acariciou-o demoradamente e confiante, montou nele. Nesse momento, o deus a raptou diante dos olhares impotentes das outras moças e a carregou pelos ares, acima do mar. O casal desapareceu no horizonte. Zeus levou Europa a Creta, retomou sua forma divina e uniu-se a Europa que, com o tempo, deu a ele dois filhos, entre eles, Minos, futuro rei de Creta e pai do Minotauro. Para recordar essa união, o touro brilha no céu como uma constelação.

Sobre a Constelação do Homem Velho (ver figura 2), de acordo com o mito Tupi-guarani, havia um homem casado com uma mulher muito mais jovem do que ele. A esposa ficou interessada pelo irmão mais novo do marido, então para ficar com o cunhado, a jovem matou o marido, cortando-lhe antes a perna na altura do joelho direito. Os deuses, penalizados, transformaram o homem em constelação (Afonso, 2006).

Segundo Costa (2009), o ser humano possui uma ação involuntária que é associar os grupos de estrelas mais brilhantes a figuras conhecidas, como em um jogo de ligar os pontos. Essas associações formam desenhos imaginários que, no céu, são as constelações. 
Criar constelações é um processo muito particular. Segundo Ress (2008), cabe às futuras gerações criarem suas próprias constelações. Portanto, a partir de uma atividade escolar, alunos podem criar suas próprias constelações e histórias, baseados em um grupo de estrelas (Pacific Science Center, 2003). Baseado nisso, a presente pesquisa tem como base constelações criadas por alunos do ensino fundamental, a partir de um jogo pedagógico.

\section{Sobre o jogo e o uso das imagens na criação de constelações}

O ser humano possui uma ação involuntária que é associar os grupos de estrelas mais brilhantes a figuras conhecidas, como em um jogo de ligar os pontos (Costa, 2000). Essas associações formam desenhos imaginários que, no céu, são as constelações. Baseado nisso, a presente pesquisa teve por objetivo conhecer as concepções que alunos do $6^{\circ}$ ano do ensino fundamental possuem sobre constelações a partir do jogo Construindo Constelações (ver figura 3). Esse jogo permite que seus participantes construam constelações, ou seja, imagens que nos ajudam a compreender as concepções que eles possuem sobre constelações, além de serem uma estratégia de ensino.

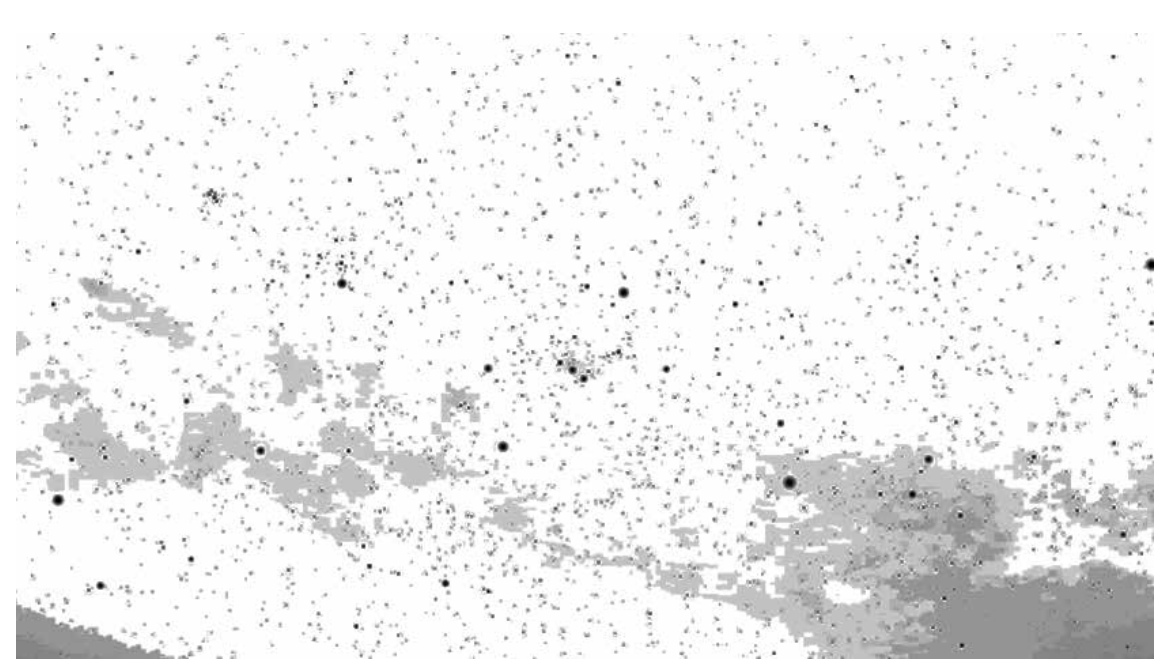

Figura 3: apresenta o jogo Construindo Constelações.

Fonte: Afonso (sd) 
O jogo Construindo Constelações pode ser classificado como jogo de construção. Esse tipo de jogo caracteriza-se como uma atividade lúdica e simbólica em que o desafio aceito pelo jogador é realizar, por exemplo, uma montagem ou arranjo de peças segundo certa referência, modelo ou intenção (Caixeta, 2012), possibilitando reconstruir o real. Quando jogamos nesta perspectiva, temos a permissão para criar livremente.

Para Vygotsky (1999), o jogo, assim como outras atividades lúdicas, geram zona de desenvolvimento proximal, ou seja, oportunidades de aprendizagem, especialmente, porque permitem a atuação do/a participante na atividade, permitem pensar sobre o contexto e tomar decisões, num ambiente de criação. Nesse sentido, o jogo, quando intencionalmente organizado, pode contribuir para o processo de formação de conceitos. Rego (2003), assumindo a teoria sócio-histórica de Vygotsky como referência, afirma que, de todos os tipos de aprendizagem, a saber: imitação, tentativa e erro e o ensino intencional, a autora destaca este último como a possibilidade mais complexa de aprendizagem, porque gera: "intenção, comunicação explícita entre duas ou mais pessoas e o uso de estratégias específicas por parte de quem ensina (p. 54).

Neste estudo, entendemos que o jogo Construindo Constelações é valoroso para a investigação da percepção de alunos sobre constelações, porque está centrado na construção de imagens e, consequentemente, de narrativas. Santaella e Noöth (1999) explicam que a imagem tem dois domínios: material - signos que representam o nosso meio ambiente visual e imaterial - imagens na nossa mente (representações, imaginações, sentidos). A leitura da imagem não é uma leitura da realidade, ao contrário, ela é uma leitura mediada por um conhecimento prévio sobre o mundo, permeada por crenças, valores, estereótipos e modelos culturais (Leite, 1998; Barthes, 1984).

Nesse sentido, a análise da imagem parada que leva em conta quatro aspectos (Peen, 2002): a) a denotação, que é a imagem por si mesma (o que aparece na imagem, cores, objetos, pessoas etc); b) sintagma, que são as relações entre os elementos que aparecem na imagem, proporções entre eles, equivalências etc (objetos, pessoas etc); c) conotação são os significados das imagens e, por fim, d) conhecimento cultural, que é o conhecimento disponível na cultura e que permite uma leitura mais coletiva da imagem, também, viabilizada pela associação da linguagem oral e/ou escrita à visual.

As imagens podem contribuir em muito para mediações nas áreas da educação e da psicologia, porque são instrumentos capazes de gerar significados, que são construídos na cultura e pela cultura, na/pela conversação com o outro. 


\section{Pesquisa Empírica}

\section{Participantes}

Participaram da pesquisa 8 alunos de uma turma do $6^{\circ}$ ano do ensino fundamental de uma escola pública de Planaltina, Distrito Federal, Brasil. A idade variou entre 11 e 12 anos. Os alunos serão apresentados nesta pesquisa com nomes fictícios: Geovana, Pedro, João, Jonas, Francisco, Amon, Augusto e Kamila. De acordo com o professor de ciências naturais da turma, os alunos ainda não haviam estudado constelações, pois ele estava seguindo o livro didático, que abordava astronomia no último módulo.

\section{Material de construção de dados}

Para construir os dados, foi utilizado o jogo Construindo Constelações (ver figura 3), desenvolvido no âmbito do projeto Escola nas Estrelas, que é um projeto de extensão da Faculdade UnB Planaltina (Xavier, 2013).

Construindo constelações é um jogo que consiste na simulação de conjuntos de estrelas e suas respectivas localizações no céu noturno, impresso em uma folha branca A4 (ver figura 3), a partir do software Stellarium. O jogo tem como objetivo estimular os alunos a criarem suas próprias constelações e suas respectivas histórias. Ao ser utilizado em sala de aula, os alunos são informados sobre o que é uma constelação, o que se trata o jogo e sobre suas regras: os pontos representam as estrelas do céu noturno e os alunos devem primeiramente observar esses pontos, para, em seguida, criar suas constelações, ligando os pontos com linhas e, por fim, criar a história da constelação no verso do jogo.

\section{Procedimentos de Construção das Informações}

Para a construção dos dados, a pesquisadora explicou aos alunos sobre o que se tratava a pesquisa, explicou o que é uma constelação, segundo a definição de constelação como agrupamentos arbitrários de estrelas (Departamento de Astronomia da UFRGS, 2009; Fares et al., 2004). Também informou que, com o jogo Construindo Constelações, eles teriam a oportunidade de criar sua própria constelação e contar a história da mesma. Explicou o funcionamento do jogo, onde os pontos eram as representações das estrelas e, ao observar esses pontos, eles deveriam criar suas próprias constelações e contar a história no verso do jogo. A pesquisadora informou o tempo de duração da atividade: 90 minutos. Após as orientações, a pesquisadora entregou um jogo a cada aluno juntamente com um lápis preto, para que eles criassem suas constelações e histórias. No decorrer da atividade, a pesquisadora caminhava pela sala, observando os alunos e tirando dúvidas referentes ao jogo.

\section{Procedimentos de análise de dados}

A análise dos dados uniu a análise semiótica da imagem parada (Penn, 2002), que foi adaptada para esta pesquisa, com a análise temática dialógica (Fávero \& Mello, 1997). Assim, no momento em que analisamos as imagens, usamos as 
histórias desenvolvidas pelos alunos como informações úteis para a compreensão delas. Para tanto, elaboramos o quadro a seguir, para realizar a análise de cada desenho e história, considerando cada participante. Assim, para os dados construídos para cada participante foi feito um quadro desses.

Quadro 1: Apresenta a tabela criada para analisar os dados.

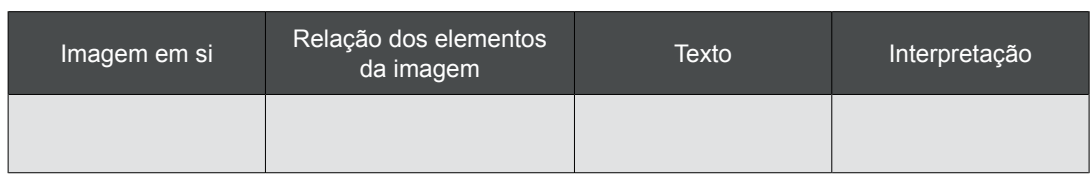

Fonte: Amador (2014)

\section{Resultados e Discussão}

Com relação às concepções de constelação que foram construídas pelos participantes da pesquisa, podemos separá-las em três grupos temáticos: constelação como céu; constelação como estrela e constelação como conjunto de estrelas.

Concepção de constelação como céu: neste grupo temático, reunimos os desenhos e histórias daqueles participantes que relacionaram constelação ao céu. Apesar de o desenho ter sido construído por meio da ligação de pontos, que representavam estrelas, os participantes não descreveram relação entre as estrelas e nem ao menos abordaram o nome constelação em suas histórias. Dos oito, dois participantes construíram esta leitura de constelação, por exemplo, a imagem e a história do aluno Jonas (ver figura 4).

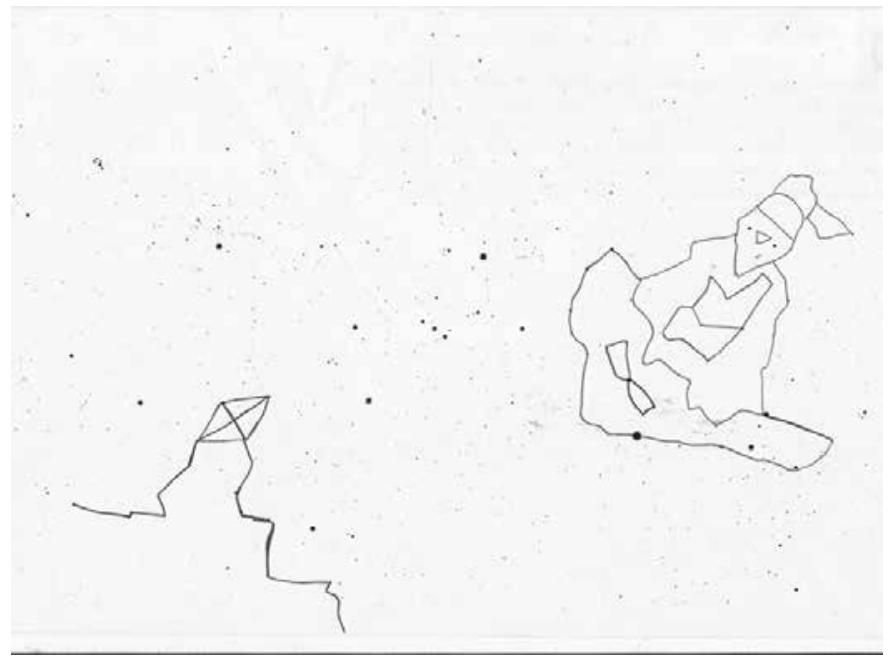

Figura 4: mostra a constelação do aluno Jonas. Fonte: Amador (2014). 


\section{O fantasma e a pipa}

“Era uma vez um fantasma muito legal, ele não era feio, chato, e nem assustador, era simpático e engraçado.

Num belo dia ele teve uma ideia quis comprar uma pipa e colocala no ferro, então depois de fazer isso a pipa subiu para o alto e viveu para o céu como um pássaro colorido, ele ficou muito feliz e batizou a pipa de pássaro colorido."

Concepção de constelação como estrela: neste grupo temático, está presente a concepção do aluno Pedro que relacionou constelação a uma única estrela. Apesar de seu desenho ter sido construído por meio da ligação de pontos, que representam as estrelas, ele não descreveu relação entre estrelas e abordou constelação em sua história como sendo uma única estrela, nomeando-a constelação de "Estrela del amor" (ver figura 5).

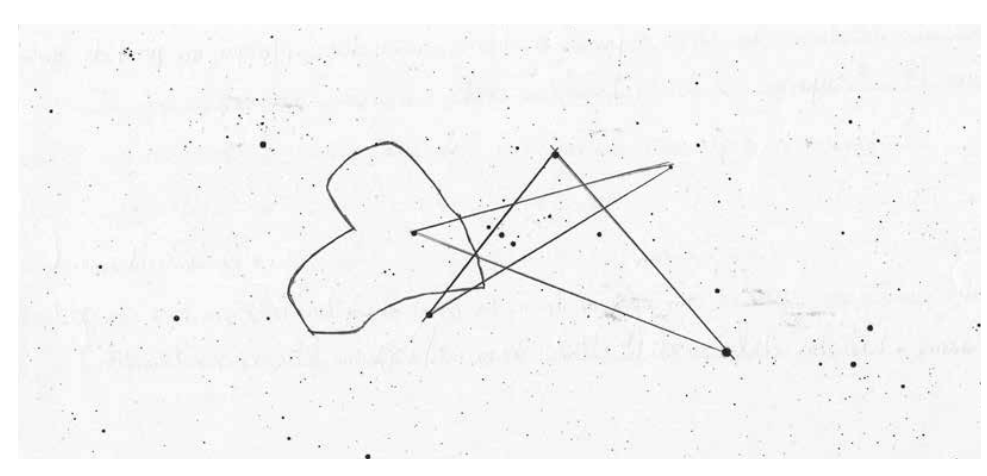

Figura 5: mostra a constelação do aluno Pedro.

Fonte: Amador (2014).

A constelação: Estrela do amor

Por Pedro

“ Era uma vez um casal que só vivia brigando, eles eram do México. Um dia decidiram se separar, mas o homem não queria, porque na verdade gostava dela. A esposa no fundo também gostava dele, mas não queria admitir.

A esposa não queria o homem em casa, mas deixou ele ficar em sua casa. Um dia ela estava andando na rua, mas não sabia que ele também estava por ali. Os dois viram uma constelação e decidiram segui-la, e se encontraram. Os dois descobrem que se amam e acabam se casando eles colocam na constelação o nome: Estrela del amor (estrela do amor) e vivem felizes para sempre”. 


\section{Revista de}

Constelação como conjunto de estrelas: cinco dos participantes demonstraram possuir a concepção de que constelação é um conjunto de estrelas. As imagens e histórias criadas por esses cinco participantes foram divididas em dois grupos: concepção de constelação estática e concepção de constelação dinâmica.

Concepção de Constelação estática: as imagens e histórias criadas por três participantes fazem parte do grupo concepção de constelação estática. Neste grupo, os participantes demonstraram possuir a concepção de que as constelações são formadas por conjuntos de estrelas, porém essas constelações não passam por transformações, elas são projeções de algo fixo (ver figura 6).

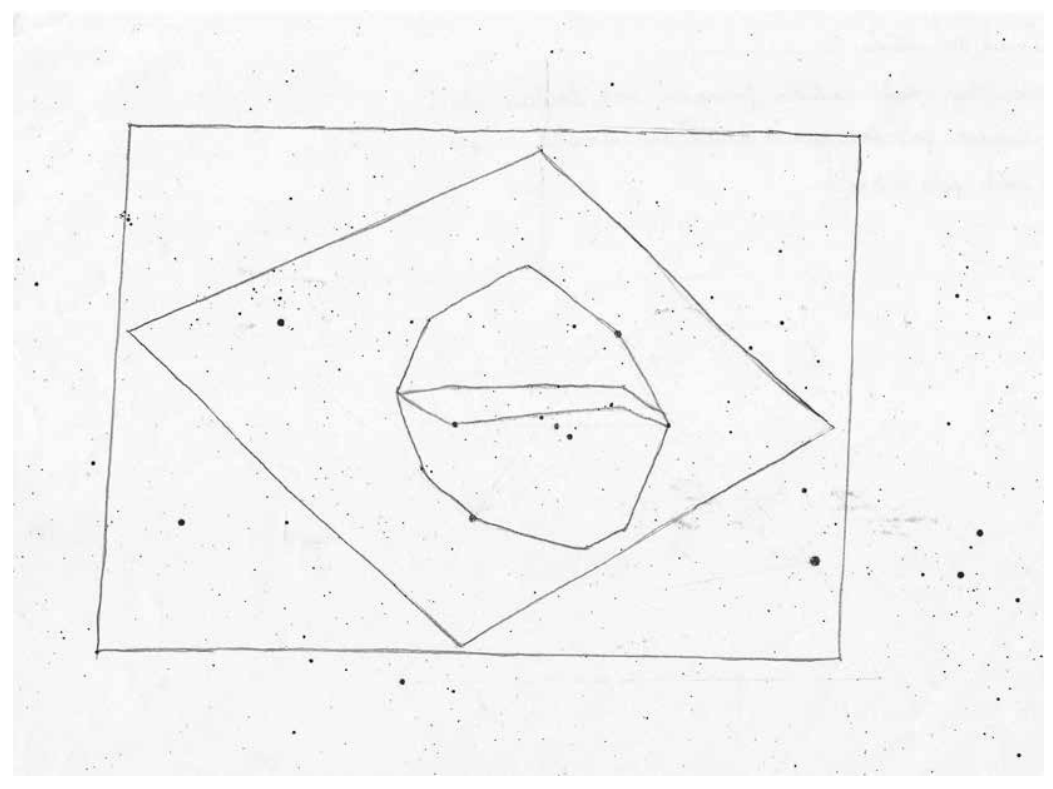

Figura 6: mostra a constelação do aluno João

Fonte: Amador (2014).

O Brasil nas estrelas

Por João

"Uma vez muitas estrelas formavam uma bandeira do Brasil e nisso falaram que o Brasil era amado e que traria sorte para o Brasil”. 
No grupo concepção de constelação dinâmica foram agrupadas as imagens e histórias de dois participantes que demonstraram possuir a concepção de que as constelações são formadas por conjuntos de estrelas e que essas constelações são passíveis de transformação e de criação. Portanto, podem ser criadas pelos ser humano. Por exemplo, Kamila trata a possibilidade de criação de uma constelação a partir de outra (ver figura 7).

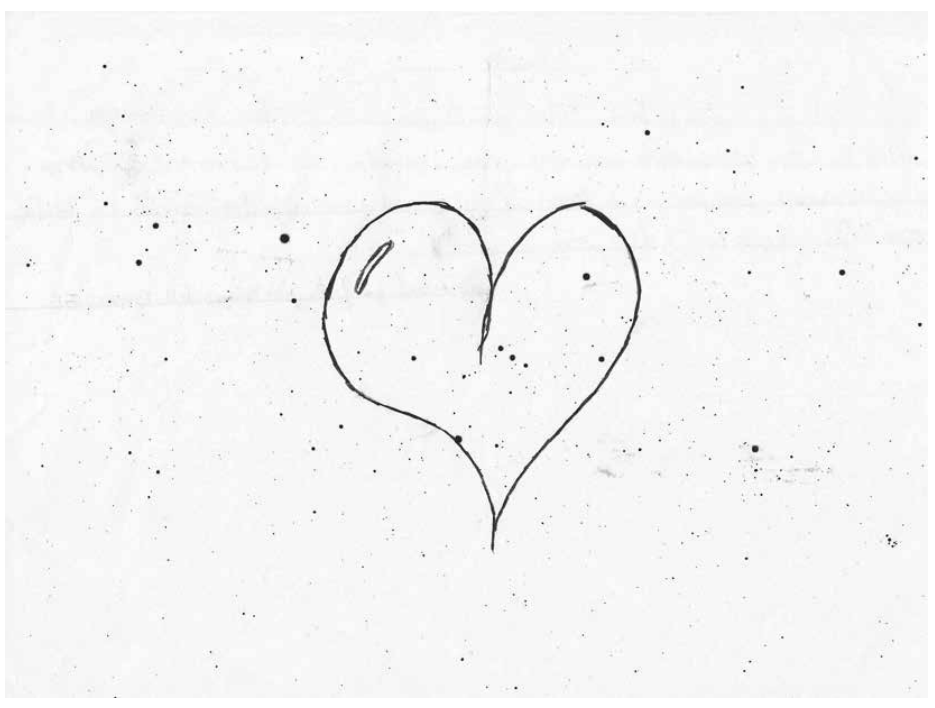

Figura 7: mostra a constelação da aluna Kamila.

Fonte: Amador (2014).

\section{Coração}

Por Kamila

"Era uma vez um coração feito de estrelas grandes, pequenas e medias. Esse coração e muito vermelho ele e tão vermelho parece que vai explodir ate que um dia estourou e todos chorava e não parava de chora até que um dia nasceu outro coração em feito de coração e todos ficaram feliz para sempre. Fim”

\section{Discussão}

A pesquisa evidenciou que nem todos os alunos possuíam uma concepção de constelação como conjunto arbitrário de estrelas (Departamento de Astronomia da UFRGS, 2009; Fares et al., 2004; Mourão, 2001), mas que a maior parte dos alunos está em processo de construção deste conceito. A prática de olhar para o céu noturno e construir constelações não é uma necessidade contemporânea dos alunos participantes da pesquisa e do seu contexto sócio-cultural. Provavelmente, 
as diferentes conquistas tecnológicas permitiram ao ser humano não ter a necessidade de olhar o céu. Portanto, as histórias construídas apresentaram temáticas que podem se associar mais à rotina de vida e interesse dos alunos, mas para uma análise mais desenvolvida, seria necessário associar a coleta de dados com o jogo a uma entrevista semi-estruturada, onde cada aluno pudesse expressar suas ideias sobre a história construída, o que não foi possível nesta pesquisa, em virtude da rotina da sala de aula.

Sobre as histórias que os alunos construíram sobre as constelações, destacamos que, mesmo todas sendo narrativas, por apresentarem dimensão de tempo, personagens, enredo, espaço e narrador (Caixeta, 2006; Gancho, 1991), elas parecem não apontar para uma correlação entre as temáticas das histórias criadas pelos alunos e as temáticas que sustentavam as histórias das constelações por gregos, romanos e indígenas, pois os alunos não narraram, em suas histórias, aspectos religiosos ou da natureza, como era feito pelos povos da antiguidade. Assim, a tarefa narrativa, solicitada no jogo, parece ter se tornado uma atividade resolução de problema que foi resolvida por eles a partir do conhecimento prévio que tinham.

Com relação ao uso do jogo Construindo Constelações, identificados que apresenta importante potencial mediador no trabalho com o conceito constelações, porque permite que os alunos, além de criarem suas próprias constelações ligando os pontos e suas histórias, aprendam a fazer a análise do seu desenho, do desenho do(a) colega e de toda a coletividade, para inferir e desenvolver conceitos relacionados à astronomia.

\section{Considerações finais}

A pesquisa evidenciou que a utilização do Jogo Construindo Constelações foi útil para a identificação de concepções que os alunos do sexto ano de uma escola tinham sobre constelações. A partir desta identificação, advinda pela análise das imagens e das narrativas a elas associadas, no jogo, é possível que professores da educação básica delineiem ações pedagógicas capazes de fomentar o ensino de conceitos de Astronomia.

\section{Referências}

Afonso, G. sd. As Constelações Indigenas Brasileiras. Observatórios Virtuais. Programas Educacionais Telescópios nas Estrelas. Disponível em: <http://www. telescopiosnaescola.pro.br/indigenas.pdf>. Acesso em: 11 abr 2014.

Afonso, G. 2006. Mitos e Estações no Céu Tupi-Guarani. Scientific American Brasil, Edição Especial: Etnoastronomia, v. 14: 46-55. 
Afonso, G. 2009. Astronomia Indígena In: Reunião Anual da SBPC, 61. Manaus, Anais. Manaus: SBPC.

Amador, A. 2013. Um estudo sobre constelações criadas por alunos do ensino fundamental. Trabalho de Conclusão de Curso (Licenciatura em Ciências Naturais)Faculdade UnB Planaltina. Planaltina.

Caixeta, J. 2006. Guardiãs da Memória: tecendo significações de si, suas fotografias e seus objetos. Tese (doutorado), Instituto de Psicologia, Universidade de Brasília, Brasília.

Caixeta J. 2012. Sobre formação de conceitos, construção de conhecimento e jogos. Texto não publicado. Faculdade UnB de Planaltina, Universidade de Brasília, Planaltina.

Centro de Divulgaçâo da Astronomia. 2000. A esfera celeste. Disponível em: http:// www.cdcc.sc.usp.br/cda/aprendendo-basico/esfera-celeste/esfera-celeste.htm. Acesso em: 6 de mai. 2014.

Clávia, A. 2010. Conhecendo as constelações: O que é constelação. Disponível em: http://www.observatorio.ufmg.br/dicas13.htm. Acesso em: 14 de abr. 2014.

Costa, F. 2009. A Constelação de Touro. UFMG - Observatório astronômico Frei Rosário. Disponível em: http://www.observatorio.ufmg.br/dicas10.htm. Acesso em: 14 de abr. 2014.

Costa, J. 2000. As 88 maravilhas do céu. Astronomia no Zênite. Disponível em: http:// www.zenite.nu?88maravilhas. Acesso em: 15 abr. 2014.

Departamento de Astronomia da UFRGS. 2009. Novo hipertexto do OEI: Constelações. Disponível em: http://www.if.ufrgs.br/oei/. Acesso em: 09 de abr. 2014.

Fares, E.; Martins, K. ; Araujo, L. \& Filhos, M. 2004. O universo das sociedades numa perspectiva relativa: Exercícios de etonoastronomia. Revista Latino-Americana de Educação em Astronomia - RELEA, n. 1: 77-85.

Fávero, M. \& Mello, R. 1997. Adolescência, maternidade e vida escolar: a difícil conciliação de papéis. Psicologia: Teoria e Pesquisa, 13 (1): 131-136.

Filho, J. \& Germano, A. 2007. Disciplina Astronomia: Contemplando o céu. Natal, RN: EDUFRN.

Gancho, C. 1991. Como Analisar Narrativas. São Paulo: Ática

International Astronomical Union. 2014. The Constellations: IAU and the 88 Constellations. Disponível em: http://www.iau.org/public/constellations/. Acesso em: 14 de abr. 2014. 
Livi, S. 1987. Abra sua janela para o céu. Caderno Catarinense de Ensino de Física. Florianópolis, 4 ( 3):158.

Mariuzzo, P. 2012. O céu como guia de conhecimentos e rituais indígenas. Cienc. Cult. [online],64 (4): 61-63.

Mourão, R. 2001. O livro de ouro do universo. 4. Ed. Rio de Janeiro: Ediouro.

Pacific Science Center. 2003. Lesson 1: Create a Constellation. Astro Adventures. Disponível em: https://journeyspace2.wikispaces.com/file/view/astro_ad_ constellation.pdf. Acesso em: 14 de abr. 2014.

Penn, G. 2002. Análise semiótica de imagens paradas. In Bauer, M. W. \& GASKELL, G.(eds). Pesquisa qualitativa com texto: imagem e som: um manual prático. Petrópolis/ RJ: Vozes.

Rees, M. 2008. As constelações. Enciclopédia ilustrada do universo: As constelações. São Paulo, Vol 4: 348-349, 2008.

Rego, T. 2003. Desenvolvimento e Aprendizagem. In Oficio de Professor: Aprender mais para ensinar melhor. Programa de Aprendizagem para professores dos anos iniciais da educação básica. Fundação Victor Civita. São Paulo.

Santos, J. 2011. Proposta de ensino em astronomia no ensino fundamental - Sistema Solar. 2011. Trabalho de Conclusão de Curso (Licenciatura em Ciências Naturais)Faculdade UnB Planaltina. Planaltina.

Vygotsky, L. 1999. A formação social da mente. São Paulo: Martins Fontes.

Xavier, R. 2013. A contextualização e o ensino de astronomia: uma análise de oficinas do projeto escola nas estrelas. Trabalho de conclusão de curso (Licenciatura em Ciências Naturais)- Faculdade UnB Planaltina. Planaltina. 